\title{
Comment based Rating Algorithm for an Online House Portal
}

\author{
Sheetal Bandekar \\ Department of Master of \\ Computer Applications \\ Gogte Institute of Technology \\ Udyambagh - Belagavi, \\ Karnataka
}

\author{
Narendra Naik \\ Department of Master of \\ Computer Applications \\ Gogte Institute of Technology \\ Udyambagh - Belagavi, \\ Karnataka
}

\author{
Arati Kulkarni \\ Department of Master of \\ Computer Applications \\ Gogte Institute of Technology \\ Udyambagh - Belagavi, \\ Karnataka
}

\begin{abstract}
The word-of-mouth has taken a new form as word-of-mouse which serves as an important parameter to publicize and recommend products or services of any company. Ecommerce has now facilitated the online users with a provision to comment or rate the products and services of any company that sells online. These comments serve as valuable information that can be used to rate products, compare products, and give valuable suggestions to online customers. Various algorithms and approaches have been implemented to rate on users' comment. This paper introduces a new approach to rate an individual product/service of a specific category, which is based on users' comments. As a case study an online house portal has been developed that sells house on rent. The new comment based algorithm is used to rate a house based on tenants' comment. This proposed algorithm is feasible and can be used for any website that sells single product/service and provides user with rating of the product/service based on customers' comments.
\end{abstract}

\section{General Terms}

Word-of-Mouse, Word-of-Mouth, User Comment

\section{Keywords}

Comment Based Rating Algorithm, Review Based Rating Algorithm, E-Commerce.

\section{INTRODUCTION}

The Word-of-Mouse concept has grabbed the Internet based branding of products allowing the consumer to decide whether to buy a product/service from a specific vendor. A number of growing websites, for example Yepl, Twitter, Urbanspoon, and Zagat serve as online guides that post customers' reviews of business and professionals, ranging from very small to large businesses such as restaurants, clothing stores, and spas, to medical and healthcare professionals, academic professors, lawyers etc. [6] The base line of deciding to go ahead with a specific product is the customers' review. These customer reviews are huge in number which may not be feasible for a customer to read all. Thus the concept of comment based or review based rating of a product has been adopted by many portals to rate products and provide recommendations. This paper proposes a new comment based rating algorithm for an online house portal. On this portal the landlords can post the details of their house or flat which they want to rent. Customers can search the house based on area. Every house is provided a rating, based on the comment given by previous tenants.

\section{LITERATURE SURVEY}

The idea of developing a new small scale algorithm for comment based rating arose by paper [1], which is basically an e-commerce website for online electronics, that provides user with a catalog of different products available for purchase with recommendation done according to rank, i.e. top ranking items are recommended to customer. Grading/Rating of product is done using review analysis based on integration of mining, sentimental analysis, and the records of customer historical behaviors. Paper [2] uses a feedback analysis system that will analyze users' reviews (collected from customers' reviews from Amazon and Snap deal) regarding different products by applying different data mining techniques like opinion mining, information filtering and sentimental analysis.

One common thing that we found out was that both these papers are focusing on comment based analysis to rate products of same kind but by different manufacturing companies that would allow a customer to make decisions base on rating provided. For instance, paper [1] has proposed an e-commerce store for books, CD's, computers, mobile phones, home appliances etc. But not all web applications are of the same kind. Paper [2] on the other hand is trying to evaluate trustworthiness of an organization for buying products. On the contrary, there are some web applications selling a single product/service. For instance a Builder could sell his apartments; College/University could sell its educational services; Hotel or chain of Hotels could sell its food or accommodation services and so on. Customer review or so called word-of-mouse is applicable for such web sites also and grading based on comment/review should be provided with a simple algorithm.

\section{PROPOSED SYSTEM}

\subsection{Overview}

This paper has implemented a simple algorithm for comment based rating on web sites that deals with the sale of a single product/service. For this, a prototype web application by name "Online House Portal" has been developed. The user on this web site has to register and then can search for a house for rent or can host the details of house to be sold out on rent. The user who wants to search for a house has to specify the location for which the web site replies by recommending a list of houses with all their details. He/She can also view the rating of a particular house based on the previous tenants' comments on the web site. The user can view all comments as well as the rating calculated based on comments. The user who wants to sell house on rent has the provision to upload details of his/her house. The calculation of the rating based on 
the comment is done by implementing entirely a new technique/algorithm that processes the given comment

\subsection{Algorithm for Comment Based Rating}

\section{Step 1: Start}

Step 2: Read the text that contains the comment

Step 3: Separate the words in the text and store them in an array

Step 4: Use a loop to read individual word in sequence from the array

Step 5: If the loop reaches the end of the array then go to Step 18 else go to Step 6

Step 6: Match the word with Grammar element (Personal Pronoun, Articles, Prepositions, Auxiliary verbs or Conjunctions) stored in the database

Step 7: If the word matches with any of the grammar element then go to Step 4

Step 8: If the word does not match with the grammar element then go to Step 9

Step 9: Check if the word belongs to a positive adjective in the database

Step 10: If yes, then increase the rating by 1 and go to Step 4

Step 11: If no, then check if the word belongs to negative adjective in the database

Step 12: If yes, then decrease the rating by 1 and go to Step 4

Step 13: If no, then check if the word matches with special phrase having positive value

Step 14: If the match occurs, then increase the rating by 1 and go to Step 4

Step 15: If match doesn't occur, then check if the word matches with special phrase having negative value

Step 16: If match occurs, then decrease the rating by 1 and go to Step 4

Step 17: If match doesn't occur then go to Step 4

Step 18: Display the final value of rating

\subsection{Results}

Following three tables gives the rating values obtained after every comment provided by different users for a specific house. For case study three different types of houses are taken into consideration. First one is an ordinary house, second one is a moderate house and the third one is an expensive house. It is to be noted that the rating keeps either increasing or decreasing based on the positive and negative connotations of the adjectives used.

\section{Table 3.1 Comments for an ordinary house}

\begin{tabular}{|l|c|}
\hline \multicolumn{1}{|c|}{ User Comment } & Rating value \\
\hline It's ok & 1.0 \\
\hline No ventilation & 0.0 \\
\hline Stuffy rooms & 0.0 \\
\hline Good but very old & 0.0 \\
\hline Simple and low cost & 0.0 \\
\hline
\end{tabular}

\begin{tabular}{|l|l|}
\hline Quite affordable & 1.0 \\
\hline It's fine & 2.0 \\
\hline Not bad & 3.0 \\
\hline
\end{tabular}

Table 3.2 Comments for a moderate house

\begin{tabular}{|l|c|}
\hline \multicolumn{1}{|c|}{ User Comment } & Rating value \\
\hline Fantastic house & 1.0 \\
\hline $\begin{array}{l}\text { Very spacious and } \\
\text { luxurious }\end{array}$ & 4.0 \\
\hline Too good & 6.0 \\
\hline $\begin{array}{l}\text { I am happy with this } \\
\text { house }\end{array}$ & 7.0 \\
\hline Wonderful & 8.0 \\
\hline $\begin{array}{l}\text { Good but at some } \\
\text { places needs repair }\end{array}$ & 8.0 \\
\hline Very nice house & 10.0 \\
\hline Lovely house & 10.0 \\
\hline
\end{tabular}

Table 3.3 Comments for an expensive house

\begin{tabular}{|l|c|}
\hline \multicolumn{1}{|c|}{ User Comment } & Rating value \\
\hline $\begin{array}{l}\text { Too good bust high } \\
\text { cost }\end{array}$ & 1.0 \\
\hline $\begin{array}{l}\text { Wonderful house but } \\
\text { high rent }\end{array}$ & 1.0 \\
\hline $\begin{array}{l}\text { Outstanding house } \\
\text { but has high rent } \\
\text { high maintenance }\end{array}$ & 0.0 \\
\hline Beautiful house & 1.0 \\
\hline $\begin{array}{l}\text { Lovely house very } \\
\text { beautiful design }\end{array}$ & 4.0 \\
\hline $\begin{array}{l}\text { Too good but not } \\
\text { affordable }\end{array}$ & 5.0 \\
\hline Very expensive & 5.0 \\
\hline $\begin{array}{l}\text { Costly house not } \\
\text { meant for middle } \\
\text { class family }\end{array}$ & 7.0 \\
\hline $\begin{array}{l}\text { Fantastic house, well } \\
\text { maintained and very } \\
\text { clean }\end{array}$ & 8.0 \\
\hline Best & 10.0 \\
\hline Superb & 10.0 \\
\hline It has a vow factor & Beautiful \\
\hline
\end{tabular}

\section{CONCLUSION}

This paper has taken into consideration the comments provided by a user specific to his/her experience as a tenant. The rating value of a house is defined within the boundary of zero to ten. The probability of usage of his/her vocabulary will be limited to specific adjectives that would describe a house, its furnishing, its environment, locality etc. Also it is very likely that the comment would be a single sentence describing his/her experience. Thus the scope of this algorithm can be extended to any web application that sells a single product/service. All that the user of this algorithm 
needs to do is to list out the adjectives used for his product/service description and use those lists that should be stored in a database. The user need not have to modify the algorithm. Thus, this algorithm can be used for small scale business enterprise selling its single product/service online where he/she anticipates simple comments which could be consisting of single sentence or simple words (adjectives) or simple phrases and use the proposed algorithm to rate or grade his/her product based on the comment provided by their customers.

\section{FUTURE SCOPE}

The proposed algorithm is limiting to the anticipated vocabulary (adjectives) in a given domain which are stored in a database. These adjectives defined which are having positive or negative values, helps in calculating the rating. Further, the parts of speech like Personal Pronoun, Articles, Preposition, Auxiliary Verbs and Conjunctions, which needs to be eliminated by the algorithm are also stored in the database. Thus, this algorithm does a scan on existing database to analyze and rate the comment. Instead of depending on a database with limited vocabulary, this algorithm can be further expanded by integrating with an online dictionary to search for the words and obtain its details like parts of speech, etymology, positive/negative connotation, synonyms etc. and perform a rather more complex sentimental analysis for grading.

\section{REFERENCES}

[1] Sameerkhan Pathan, Shahrukh Khan, Mohammad Arshad, Amir Ahmad and Anand Bali, "Comment Based Grading and Rating System in E-Commerce", International Journal of Engineering Research and General Science Volume 3, Issue 1, January-February, 2015. ISSN 2091--2730

[2] Sonali J. Bagul, Prof. Rakhi D. Wajgi, "Design Feedback Analysis System for E-Commerce Organization”, IEEE Sponsored World Conference on Futuristic Trends in Research and Innovation for Social Welfare (WCCFFTR'16)

[3] Arun Monicka Raja M., Godfrey Winster S., Swamynathan S., "Review Analyzer: Analyzing Consumer Product Reviews from Review Collections", IEEE International Conference on Recent Advances in Computing and Software Systems 2012.

[4] Andrew J. Flanagin, Miriam J. Metzger, Rebekah Pure, Alex Markov, "User-Generated Ratings and the Evaluation of Credibility and Product Quality in Ecommerce Transactions", In proceedings of Department of Communication, University of California, 2011.

[5] B. Sarwar, G. Karypis, J. Konstan and J. Riedl., "Analysis of Recommendation Algorithms for ECommerce", In proceedings of ACM E-Commerce, 2010.

[6] Word-of-Mouse vs. Word-of-Mouth Advertising Available:https://isenbergmarketing.wordpress.com/2015 /01/04/word-of-mouse-vs-word-of-mouth-advertising/ 